\title{
Proposal of Meteorological Minishelter as a Subsidy for Research and Teaching of Climatology
}

\author{
Yara Batista Gomes \\ Student of the Geography Academic \\ Master's Course at Acaraú \\ Valley State University (UVA) \\ Isorlanda Caracristi \\ Professor of Geography Courses and Academic \\ Master in Geography at Acaraú \\ Valley State University (UVA)
}

\begin{abstract}
This article deals with the production of materials and data for the aid of practical classes in Geography, based on the TCC research developed in the Bachelor's Degree in Geography at the Acaraú Valley State University (UVA). The confection of PVC minishelter for meteorological equipment allocation, aiming at the production of primary data in the area of geographic climatology, as an alternative to the lack of existing equipment in the Brazilian public institutions, is the main focus of the present work. For this purpose, Gomes (2019), Gomes and Caracristi (2019), Moreira (2011), Pacheco; Barbosa and Fernandes (2017), Venturi (2006) and Castelhano and Roseghini (2011) were used as main references. Contributing to the improvement of the teaching-learning process of Climatology contents both in the initial formation of the geographer and in Basic Education is what is intended with the results presented here.
\end{abstract}

Keywords: Initial training, Research Practices, Production of materials and data.

\section{Introduction}

The initial formation in Geography requires criticality and inseparable relationship between theory, practice and experienced reality, this inseparability becomes concrete when the subjects analyze/observe the part of the whole from a perspective integrated to the natural and social dynamics that produce the geographic space. To this end, academics are guided to understand theory and practice in an interconnected manner, understanding the reality in which it is inserted as a process that it can act and transform.

Theoretical-methodological contributions form the basis for understanding concepts that are put into practice through techniques that should permeate the formation of the geographer, whether bachelor or graduate. The development of the Course Conclusion Work (TCC), especially the monograph, plays a fundamental role in the theoretical and practical exercise of everything that has been learned throughout the formation, especially when the TCC requires laboratory and field activities, reflecting the relationship between teaching and research, which produces better professional qualification, as emphasized by Tardif (2000).

In their practice, professionals should rely on specialized and formalized knowledge, mostly through scientific disciplines in a broad sense, including, of course, natural and applied sciences, but also social sciences and humanities, as well as education sciences. This expertise must be acquired through long, high-level training, most often of a university or equivalent nature (TARDIF, 2000, p. 6).

In this context, the present article addresses the field research experience of End of Course Work (TCC) in the Bachelor of Geography Course, focusing on the elaboration/confection of meteorological mini-shelter focused on the production of primary climatological and climate data, as an alternative to the lack of official data and in substitution of the conventional shelters unavailable in the laboratories, aiming to contribute with the development of resources and techniques to subsidize practical classes and field researches, directed to the Geographic Climatology and how these practices have great pedagogical-scientific potential to help in the initial formation in Geography.

\section{The Relationship between Initial Training and Laboratory and Field Practices}

In the training of future Geography professionals, the practices carried out in the laboratory/field must be taken into account and how the application of such practices can support the learning process and initial training, because theories discussed and reflected practices carried out in the laboratory and in the field are complementary, so that the teaching-learning process is significant (MOREIRA, 2011) both for the future graduate and bachelor in Geography. 
According to Title V of the Education Guidelines and Bases Law (LDB 9.394/96), which deals with the levels and modalities of education, Article 43 highlights the competencies and skills needed for higher education:

I - to stimulate cultural creation and the development of scientific spirit and reflexive thinking; II - to train graduates in the different areas of knowledge, suitable for insertion in professional sectors and for participation in the development of Brazilian society, and to collaborate in its continuous formation. III - to encourage research work and scientific investigation, aiming at the development of science and technology and the creation and diffusion of culture, and thus develop the understanding of man and the environment in which he lives; IV - to promote the diffusion of cultural, scientific and technical knowledge that constitute patrimony of humanity and communicate knowledge through teaching, publications or other forms of communication; VI - to stimulate the knowledge of the problems of the present world, particularly the national and regional ones, to render specialized services to the community and establish with it a relationship of reciprocity; VII - to promote the extension, open to the participation of the population, aiming at the diffusion of the achievements and benefits resulting from the cultural creation and scientific research generated in the institution (BRAZIL, 1996).

Significant learning "is characterized by the interaction between new knowledge and previous knowledge" (MOREIRA, 2011, p. 225), being significant the relationship of the apprentice with his knowledge,

In meaningful learning, the apprentice is not a passive receiver. Far from it. He must make use of the meanings he has already internalized, in a substantive and not arbitrary manner, in order to grasp the meanings of educational materials. In this process, while he is progressively differentiating his cognitive structure, he is also making integrative reconciliation in order to identify similarities and differences and reorganize his knowledge. In other words, the learner builds his knowledge, produces his knowledge (MOREIRA, 2011, p. 226).

Therefore, it is extremely important to have a meaningful understanding of the theoretical and practical aspects in the training process:

Theory is the way knowledge presents itself systematically articulated in degrees and specificities, willing to explain or illustrate practical actions; while practice is the constitution of theory, formulated in concrete actions, which can be modified and modify theories. Considering this context, it is evident that both are intertwined and that the untying of these weakens the learning process of the subject (PACHECO; BARBOSA; FERNANDES, 2017, p. 334-335).

The reality presented through theoretical knowledge is adequately glimpsed when the conceptual discussion is permeated with practical actions. In the case of field work, pre-field planning activities (selection of maps, charts, equipment, technical-methodological procedures, etc.) performed in the office, become essential, as well as postfield procedures (tabulation of data obtained in the field, generation of graphs, verification and analysis of results, etc.) in the laboratory, which are as important as the field work itself, which consists of ample observation and critical reflections, aiming at better understanding the reality of the interactions of the object of study. Venturi (2006, p. 74-75) makes an analysis of the process of systematization of these tasks by stating that

In many cases, the use of technique can be divided in two moments: the laboratory and the field. The laboratory (from Latin, labor = work and thorium = place where an action is practiced) is being considered a place of labor, of work, equipped with its own apparatus or not. The cabinet is incorporated in this sense. In general, the division between the cabinet and the laboratory clearly occurs in specialties that require the use of more specific instruments, such as Pedology and Climatology. In these cases, the cabinet is generally used for planning and preparing the field work and the laboratory, strictly speaking, for the work of systematizing the information gathered in the field.

The practices experienced in the field, laboratories or classroom, awaken creativity, encouraging the search for knowledge through the practice of scientific research. New ways are opened to understand a given reality, and that can/should lead the future geography teacher to rethink possibilities of didactic transposition in his classes in basic education, because the reality experienced is a way to develop in the future teacher his critical-reflective potential (LINS, 2019), as well as improve the analytical capacity of perception and observation of the bachelor geographer who will work in consulting, advisory and other technical services. For Venturi (Op. Cit.),

the moment of field work represents the scientist's immediate contact with reality, even if he can make use of instruments; it is the moment to know it better through observation and interpretation techniques (two aspects of the same process, since it is the subject who observes, not his sensory organs), instrumentalized or not (VENTURI, 2006, p. 75).

In this sense, teachers and students, whether in university education or basic education, are considered reflective subjects and protagonists in the teaching-learning process, the teacher being the mediator of this process - contrary to what the traditionalist scholastic model thought. 
Roethig (2014, p. 275) states that "the planning and organization of a Field Work and a Study of the Environment is much richer if done in a group and in a shared way", facilitating the dialogue between students and the teacher, through the range of different perceptions acquired by living these practices. We return here to what Moreira's (2011) significant critical learning proposes - and any other methodology based on the assumptions of Paulo Freire or Aussubel, for example.

The analysis of the social/natural aspects that make up the dynamics of the geographic space permeates the formation of the geographer, aspects obtained by direct contact with the practice in the field. As Venturi (Op. Cit., p.76) points out, it is essential to "be aware that the field and the information that can be obtained there are irreplaceable. In other words, it is through the field that a wider and more concrete perception of theoretical knowledge is obtained, adding valuable empirical knowledge to geographical formation.

\section{The Production of Materials and Primary Data: Challenges and Surpasses}

Difficulties and shortcomings in relation to practices for the development and execution of field and laboratory work are quite common in academic and scientific training, especially in public institutions.

The lack of financial resources in the institutes and departments of Brazilian public universities makes it difficult to acquire adequate equipment for research development. This situation, on the other hand, stimulates the creation and development of low-cost equipment that can be applied scientifically (ARMANI; GALVANI, 2006, p. 116).

From the perspective of data production in geographical science, more specifically in climatology, a considerable number of scientific instruments is necessary, because,

When it comes to climatology, field work, aimed at obtaining primary data, involves much more than just observation and analysis, usually aimed at obtaining data on relative humidity, rain and temperature, for example, data that can only be obtained through the use of specific equipment for this purpose, which are placed in the socalled mini weather shelters distributed at research sites (CASTELHANO; ROSEGHINI, 2011, p. 48).

Faced with considerable costs, the absence or discrepancy of available scientific instruments, the challenge is to seek to produce with accessible, according to Pereira and Caracristi (2020), and often proprietary resources materials that present in their essence the same functionality as those instruments. In this way, according Hoppe's affirmation,

alternatives are put into practice in order to develop tools and craft mechanisms capable of meeting the demand required by climate studies (temporal and/or seasonal) (HOPPE; et.al, 2015, p. 133).

In an attempt to overcome the lack of material conditions to carry out research activities fundamental to professional training and the fulfillment of the social and scientific role of a public university, teachers and students, maintaining the parameters of the rigor of scientific research and the levels of margin of error and accuracy, develop, manufacture and adapt equipment and instruments for data collection and analysis, in a creative and responsible manner. The confection of meteorological mini shelters for the conditioning of climate measurement instruments, is an example of this creative process of overcoming.

In this sense, the academic autonomy on the part of teachers and students in searching for more accessible and possible alternatives to overcome the difficulties in obtaining scientific equipment/instruments essential for the development of research activities is important. And in this way, provide the expansion of knowledge, outlining new ways to overcome the difficulties encountered in doing research, both within and outside the academic sphere.

\section{The Option for the Mini Pvc Weather Shelter}

The option for the own production of PVC mini shelter to condition the climatic measuring instruments, aiming to enable the production of primary data essential to the execution of TCC research, was based on the technicalmethodological procedures elaborated by Castelhano and Roseghini (2011), which used Polyvinyl Chloride, as material for the construction of meteorological mini shelter. The use of this raw material in the field of action already explains a knowledge of the reality and local conditions, ensuring the practicality, functionality and cost reduction of field work in Geographic Climatology.

The study developed by these authors proved the efficacy of the PVC shelters, because the data obtained were similar to those collected in the traditional wooden shelters, such as those used by Muniz and Caracristi (2019), as well as they approached, with minimum margin of difference, the values of the same parameters found in the official site of the National Institute of Meteorology - INMET for the same place and period. Figure 1 shows the meteorological mini shelter model schematized by Castelhano and Roseghini (2011). 
Figure 1 - Structure diagram of the PVC mini weather shelter

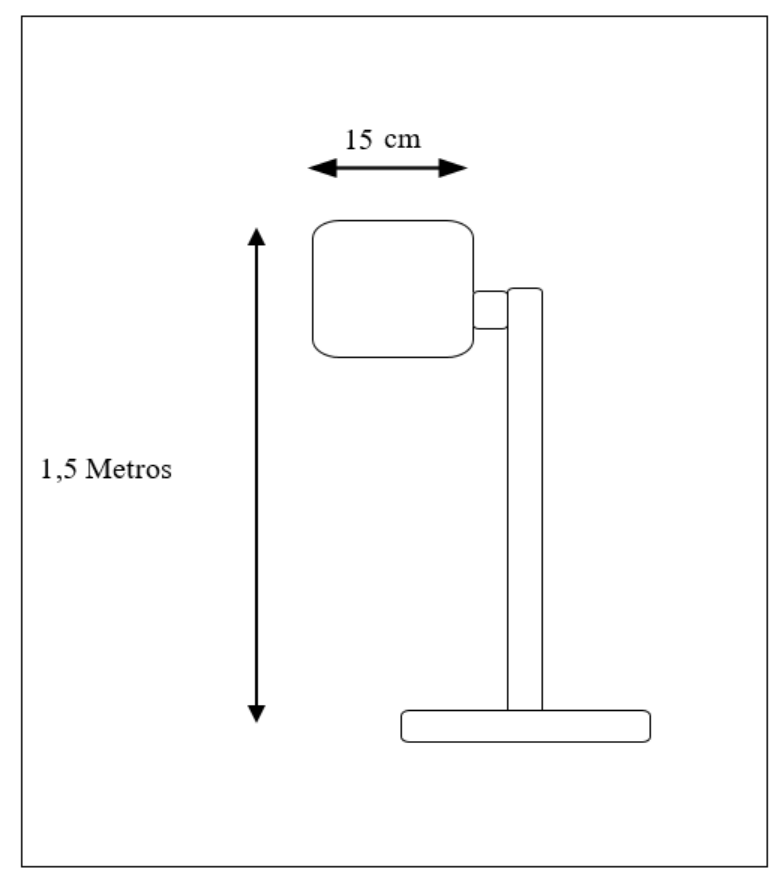

Source: CASTELHANO E ROSEGHINI (2011)

Regarding its chemical properties, Polyvinyl Chloride, popularly known as PVC, widely used in the architecture and construction sector, is composed of $57 \%$ chlorine and $43 \%$ ethylene (PVC, 2018). The choice of this material was due to the following advantages: (1) it is considered a good thermal insulator, surpassing even wood materials (a characteristic that suits very well the field works in the Climatology area, where the equipments are more easily exposed to the influence of the climatic storms as solar radiation, winds, precipitations, air humidity(2) the accessibility/availability of acquisition; (3) the low cost in the confection; (4) the lightness of the material, which facilitates the transportation; (5) optimization in the confection time and; (6) practicality in the equipment assembly.

\section{Proposal of Meteorological Mini Shelter Confection Focused On the Practice of Climatology Teaching}

Based on the experience gained during the development of CBT research, the following considerations will be made and the proposal of a mini shelter as a resource for field research practice that can be applied both in the teaching of Geography at a higher level and in basic education, with the teacher being responsible for adapting it to the reality of the school and the student.

The professional who works in the teaching of Geography science does not always have the necessary resources available for the realization of practical classes, in face of the issues mentioned above. "Currently, the main proposals to overcome the purely expository classes are through field activities / middle studies" (MUNIZ, 2010, p. 24). It is in this context that the construction of tools/materials for the execution of more dynamic and participatory classes can contribute more effectively to teaching-learning and the construction of scientific knowledge.

The manufacture of meteorological shelters, according to conventional standards, usually has considerable costs or demands more time in its confection. Aiming at a low cost-benefit in its manufacturing associated to the scientific efficiency, a good proposal is the confection of a PVC mini shelter that would be viable for the execution of practical field classes or field research stage, without losing the effectiveness and reliability, counting on PVC pieces easily found in any local construction store.

For the development of the study or practical class of microclimate, topoclimate or local climate, be it in urban or rural areas, it is necessary the field measurement of the climatic parameters of temperature, relative humidity of the air, winds and pressure. In the case of the measurement of temperature and relative humidity of air, which are the most important parameters recorded by instruments that need weather shelter, the data can be obtained through analog or digital equipment as a thermometer. Generally, analog instruments are chosen because they are cheaper and quickly purchased online (over the internet).

It is important to emphasize that these instruments (analog) do not present the same precision as the more sophisticated equipment (usually digital), however, they can supply the needs and the demand for the acquisition of 
primary climatic data focused on local analysis, as Gomes and Caracristi (2019) point out. Generally, such data is fundamental, since not all municipalities have a weather station to collect secondary data.

First of all, it is necessary to elaborate a sketch of the type of PVC shelter to be made, keeping in mind the specificities of the instruments and the measurement place, because urban places or places with a lot of ventilation will require that the shelter has a heavier or bigger base to keep the shelter standing. As well, place or period of the year very rainy will require to adapt the shelter to not enter water in its interior.

The defined type of shelter will also determine the size and quantity of parts such as tubes, pipes, fittings and housings, as well as tools and materials that will assist in the manufacturing process, such as tape, blades/cutting saws and plastic adhesive, as shown in figure 2.

The mini shelter should be positioned at a height of $1.50 \mathrm{~m}$ from the ground (measured from the vertical pipe of the shelter), as shown in figure 3, to reduce the interference of the heat emitted by the ground in the records of the meteorological instruments, according to the guidelines established by the World Meteorological Organization (WMO).

Figure 2 - Materials used to make the mini shelter
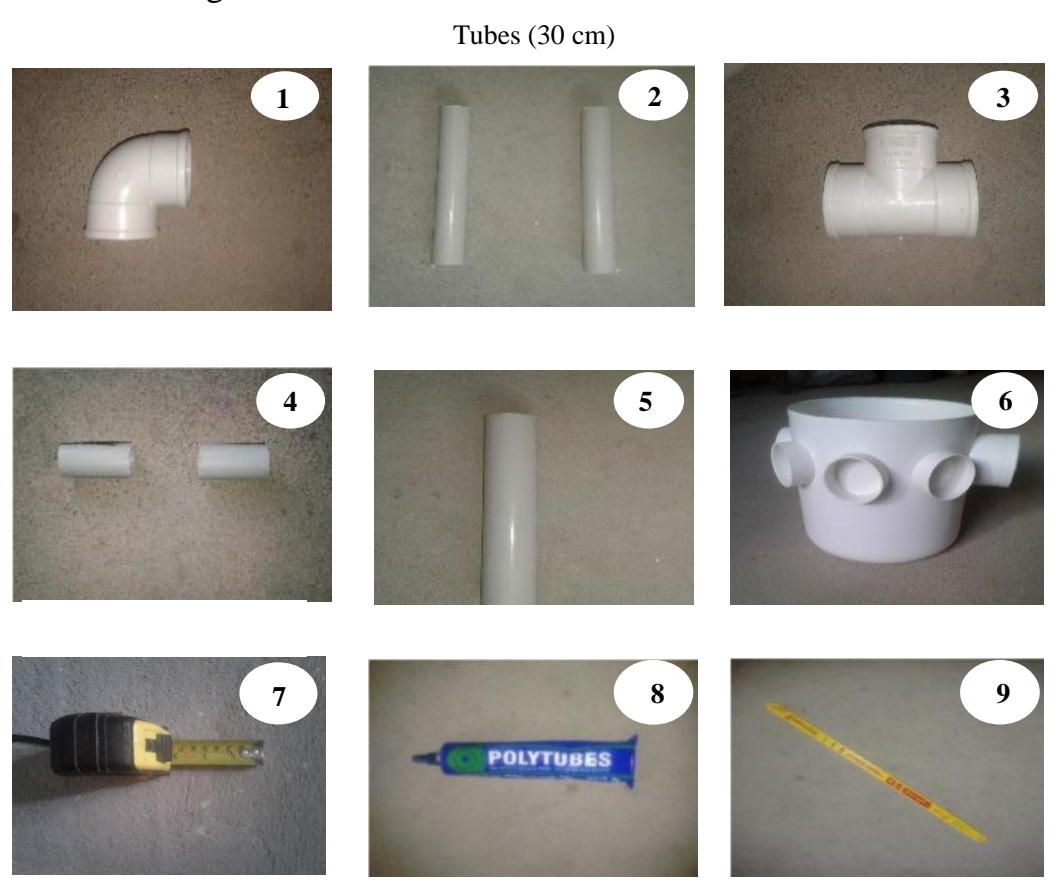

Source: GOMES (2019)

Figure 3 - Mini shelter set up

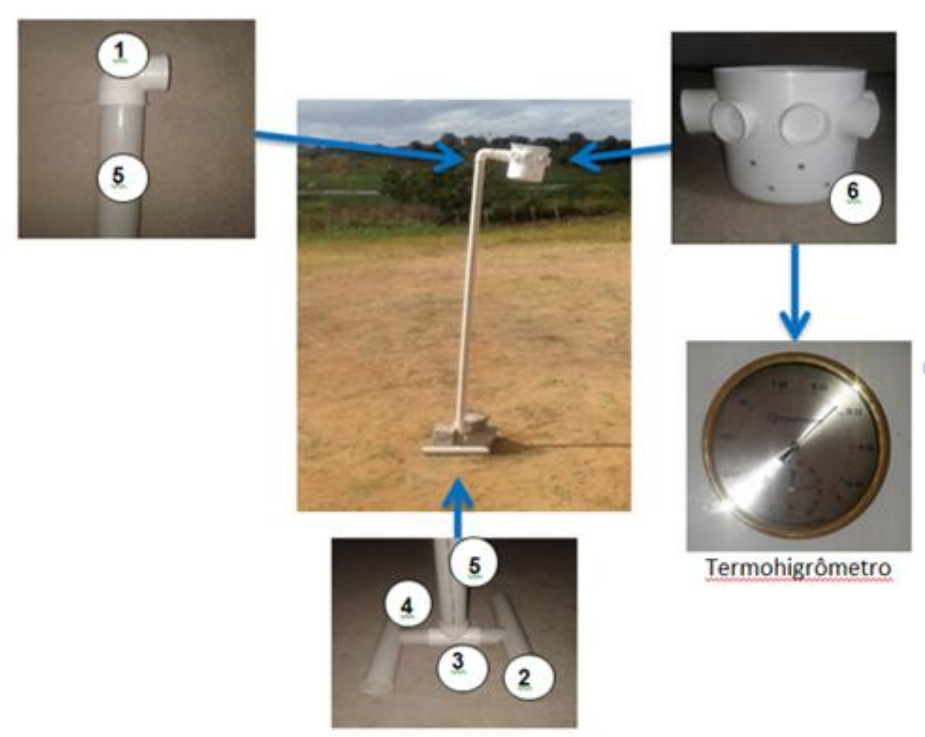

Source: GOMES (2019) 
The manufacture and use of the mini shelter will provide the subsidy of field work in the classes and research of Climatology, from the empirical experience of the students when having direct contact and handling of climatic/meteorological instruments and in the measurement, tabulation and analysis of data produced in the field experiences that contribute to the effectiveness and improvement of the teaching-learning process.

\section{Application of Mini Shelter in Field Research}

Given the need for primary data, the variations in air temperature and relative humidity parameters were measured. These data were obtained through the use of three thermometers inserted in three meteorological mini shelters, which were distributed in Data Collection Stations - PCD's figure 4 in distinct areas of the city of Forquilha, located in the northwestern region of the state of Ceará.

The collection was carried out on July 5, 2019, in the morning and afternoon periods. The measurements were made every hour and simultaneously in the three PCD's, starting at 9:00 a.m. and ending at 3:00 p.m.

Figure 4 - Data Collection Posts - PCD`s

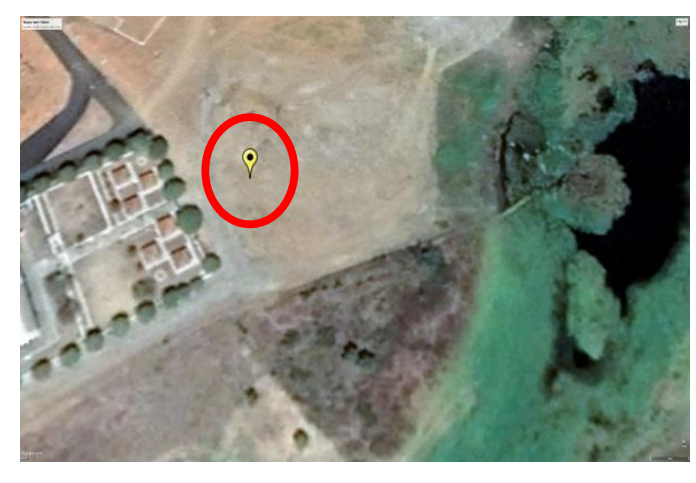

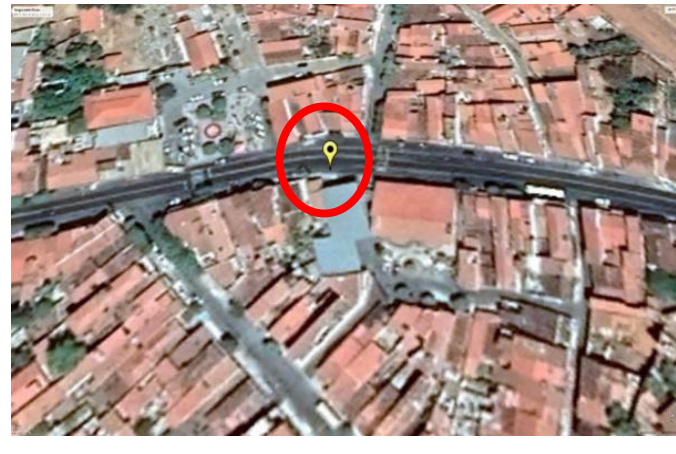

Source: EARTH (2019)

Bringing some of the results obtained through the collection of climatic data using the mini shelter, it was verified at the point referring to the Forquilha'sBalneary, temperature (T) of $31.5^{\circ} \mathrm{C}$ and relative humidity (UR) of the air of $64 \%$ at 12:00h. In the other PCD's, Municipal Public Market was $38^{\circ} \mathrm{C}(\mathrm{T})$ and $46 \%$ (UR) and EC Margins - 362 registered $36^{\circ} \mathrm{C}(\mathrm{T})$ and $52 \%$ (UR) also registered high temperatures and low relative humidity of the air at the same time. The high temperatures and low humidity registers were maintained in the three PCD's, throughout the period of data collection (9:00 am to 3:00 pm).

The variations and margin of error of the registers of the parameters of temperature and relative humidity of the air, correspond to what is empirically and scientifically expected in the studied environmental context and by the level of precision of the term analogical hygrometer used, validating the application of the PVC mini shelters in the researches of geographical climatology.

\section{Final Considerations}

The recurrence of difficulties in performing academic/scientific research and practical classes in the Brazilian public educational environment, especially in the acquisition of materials, requires that the professional in training create conditions that enable the practices of research in the laboratory and field, for his formation as a geographer. The meteorological mini shelters made with PVC pieces show to be an accessible and low-cost alternative, which, in a certain way, amplifies the advances of Climatology researches. 
For this reason, they can be implemented for the realization of practical laboratory/field classes that work with the obtaining and measurement of primary data, especially in the classes directed to Geographic Climatology, in order to contribute to the initial formation in the scope of the modality's graduation and bachelor's degree in Geography or even in the Basic Education.

The need to make up one's own research materials leads to a previous search which also constitutes a research activity in itself, as it requires surveys and studies on the alternatives used by other authors and requires reflexive creativity based on the theoretical precepts learned and the practical experiences acquired, to adapt, redo and create the best form, processes, materials and resources in the face of the reality experienced and the objectives of the research. In overcoming difficulties, the geographic formation becomes doubly effective.

\section{Acknowledgments}

To the Coordenação de Aperfeiçoamento de Pessoal de Nível Superior (CAPES) (Coordination for the Improvement of Higher Level Personnel).

\section{Bibliographical References}

ARMANI, Gustavo; GALVANI, Emerson.Evaluation of the performance of a low-cost weather shelter.Brazilian Journal of Agrometeorology, Piracicaba-SP, v. 14, n.1, p. 116-122, 2006.

BRAZIL. Law of Guidelines and Bases of National Education No. 9.394, of 20

of December 1996.

CASTELHANO, Francisco; ROSEGHINI, Wilson. The use of Polyvinyl Chloride (PVC) in the construction of mini weather shelters for field application.Brazilian Journal of Climatology, v. 9, p. 48-55, 2011.

GOMES, Yara Batista; CARACRISTI, Isorlanda.Urban climate and thermal perception of the inhabitants of small towns in the semi-arid: an analysis of the city of Forquilha (CE). Sobral, Man, Space and Time Magazine (RHET), v. 13 n. 2 p. 67-81, 2019.

GOMES, Yara Batista. Contribution to studies of urban climate in small towns in the context of the semi-arid: the case of the city of Forquilha (EC). 2019. Monograph (Bachelor of Geography) - UniversidadeEstadual Vale doAcaraú, Sobral, 2019.

HOPPE, Ismael Luis; et. al. Comparison between a low-cost meteorological shelter and the official weather station at INMET, in Santa Maria (RS).Science and Natura, v. 37, ed. Especial SIC, p. 132-137, 2015.

LINS JÚNIOR, José RaymundoFigueiredo. Linguistic education and critical-reflexive teacher training: an analysis of the speeches of the graduates of the UEVA Literature course. Thesis (Doctorate in Linguistics) Graduate Program in Linguistics,Federal University of Paraíba.João Pessoa, 183 p. 2019.

MOREIRA, Marco Antônio. Learning Theories. São Paulo: E.P.U. $2^{\text {a }}$ Ed. ampl., p. 242, 2011, cap. 15.

MUNIZ, Francisco Gerson Lima; CARACRISTI, Isorlanda.The perception of the population with the climate of the city of Sobral - CE. Teresina, Equador Magazine, v. 08, Series 02, p. 449 - 467, 2019.

MUNIZ, Francisco Gerson Lima. The construction of teaching materials as a technique for learning geographical climatology in the early grades of elementary school. 2010. Monograph (Degree in Geography) - Acaraú Valley State University, Sobral, 2010.

PACHECO, Willyan Ramon de Souza; BARBOSA, João Paulo da Silva; FERNANDES, DorgivalGonçalves.The relationship theory and practice in the process of teacher training.Interdisciplinary Research Journal, Cajazeiras, n. 2, suplementar, p. 332- 340, sep. 2017.

PVC, Brazilian Institute of.Available at: https://pvc.org.br/ access at: 20 mai. 2019.

PEREIRA, ClelfaMonteiro; CARACRISTI, Isorlanda.Experimental activities such as teaching-learning practice of physical geography subjects in high school.Journal of Northeast Geosciences, Caicó, v.6, n. 1, 2020.

ROETHIG, Camila. The limits and possibilities of field work and the rigor in teaching geography.IV Regional Meeting of Geography Teaching, Campinas, 2014, p. 270-282.

TARDIF, Maurice. Professional knowledge of teachers and university knowledge: elements for an epistemology of the professional practice of teachers and its consequences in relation to training for teaching.Brazilian Journal of Education, n. 13, 2000.

VENTURI, Luis Antonio Bittar. The role of technique in the scientific production process.Paulista Geography Bulletin.São Paulo, n. 84, p. 69-76, 2006. 